\section{Variation of availability and frequency of emergency physician-performed ultrasonography between adult and pediatric patients in the academic emergency department in Korea}

\author{
Chiwon Ahn', Changsun Kim', Bo Seung Kang', Hyuk Joong Choi', \\ Jun Hwi Cho ${ }^{2}$ \\ 'Department of Emergency Medicine, Hanyang University Guri Hospital, Hanyang University College of \\ Medicine, Guri, Korea \\ ${ }^{2}$ Department of Emergency Medicine, Kangwon National University School of Medicine, Chuncheon, Korea
}

Objective This study investigates the availability and frequency of emergency physician-performed ultrasonography (USG) in the emergency department (ED) and the status of USG training programs in emergency medicine residencies in academic EDs in Korea.

Methods In spring 2014, a link to a 16-question, multiple-choice, and rating scale web-based survey was e-mailed to all 97 academic ED residency training directors in Korea.

Results The response rate was 83.5\% (81/97). All respondents had their own USG machines in the ED. In total, $82.7 \%$ of respondents reported that emergency physician-performed adult USGs were usually conducted daily, whereas only $23.6 \%$ performed pediatric USGs daily. Moreover, $55.5 \%$ performed pediatric USG fewer than once a week. $74.1 \%$ of respondents had education programs for adult USG in residency training, but only $21.0 \%$ had programs for pediatric USG. There was a high association between the presence of education programs and the use of USG in both groups. The faculty members who most commonly participated in teaching ED residents how to perform USG were emergency physicians (67.9\%). Only 17.3\% of respondents reported that they always supported a quality assurance process. The training directors generally agreed with the advantages in emergency physician-performed USGs.

Conclusion The availability of ultrasound machines was high both for adult and pediatric EDs. Nevertheless, the frequency of Emergency physician-performed USG for pediatric patients was low, which was related to the lack of the training programs for treating pediatric patients.

Keywords Pediatrics; Ultrasonography; Emergency service, hospital; Internship and residency; Education

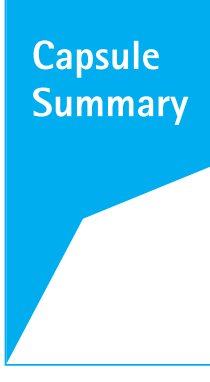

What is already known

Bedside ultrasonography by emergency physicians in the emergency department has many advantages.

What is new in the current study

We found a high association between the availability of education programs and the use of Itrasonography.
elSSN: 2383-4625

Received: 11 July 2014

Revised: 25 July 2014

Accepted: 10 August 2014

Correspondence to: Changsun Kim Department of Emergency Medicine, Hanyang University Guri Hospital, 153 Gyeongchun-ro, Guri 471-701, Korea

E-mail: flyes98@hyumc.com

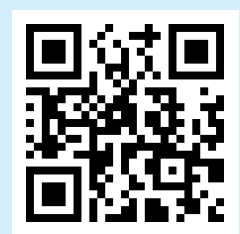

How to cite this article:

Ahn C, Kim C, Kang BS, Choi HJ, Cho JH. The differences in the availability and use of emergency physician-performed ultrasonography between adult and pediatric patients at the academic emergency department in Korea. Clin Exp Emer Med 2015;2(1):16-23.

This is an Open Access article distributed under the terms of the Creative Commons Attribution Non-Commercial License (http:// creativecommons.org/licenses/by-nc/3.0/). 


\section{INTRODUCTION}

As first described in the 1980s, using bedside ultrasonography (USG) by emergency physicians in the emergency department (ED) has many advantages; for example, it can be performed 24 hours a day and is easily accessible. In addition, it can contribute to shortening ED stays and improving patients' satisfaction and quality of care. ${ }^{1}$ Emergency physicians should be able to perform USG at any time; therefore, bedside USG training should be required in emergency medicine (EM) residency training programs. The guidelines for bedside USG training were first published by the American College of Emergency Physicians in 1991 and were revised in 2001. ${ }^{2}$ The Accreditation Council on Graduate Medical Education stipulates that ED bedside USG is one of 15 essential procedures that should be acquired during EM residency ${ }^{3}$ and that ultrasound training should be included in EM residency training programs in the United States. Bedside ultrasound training is also mentioned in the EM residency training program as core content for emergency procedures in Korea; however, pediatric emergency USG is not included. We hypothesized that this pediatric emergency USG policy by the Korean Society of Emergency Medicine (KSEM) may result in a lack of education programs for pediatric USG during residency training. As a result, the use of pediatric USG by emergency physicians may be low.

There has been no previous research reporting ultrasound use, especially on pediatric patients in academic EDs in Korea. Therefore, in this study, we investigate the current status of using emergency physician-performed USGs and assess whether there are differences in the availability and use of this technique between adult and pediatric patients in academic EDs in Korea. We also investigate the presence or absence of USG training programs in each group and analyze the correlation between the presence of a training program and the current practice of bedside USGs performed by emergency physicians.

\section{METHODS}

\section{Study design and setting}

A self-administered questionnaire was emailed to all EM educational directors at teaching hospitals in Korea; the survey was created with a Google web service. A list of all EM educational directors at each hospital was obtained from the KSEM. The questionnaire comprised 16 items that related to the availability and use of emergency physician-performed USG, the status of ultrasound education in EM residency training programs, and the directors' perception of emergency physician-performed USG use (Appendix) .The questionnaire was devised through a consensus of two board-certified emergency physicians on the basis of previous studies. ${ }^{4,5}$

Permission to conduct this study was obtained from the Institutional Review Board of Hanyang University Guri Hospital.

\section{Data collection and measurement}

The survey was conducted in spring 2014 and the educational directors of 97 academic EDs in Korea were contacted. Several additional e-mails were sent to those who missed the previous survey with telephone calls at 1-week intervals. No financial compensation was provided for participation. We obtained the numbers of faculty members and residents at each hospital as reported by the KSEM. The number of patients who visited the ED annually in the enrolled teaching hospitals was obtained from the National Emergency Medical Center.

\section{Primary data analysis}

Data were entered into SPSS ver. 18.0 (SPSS Inc., Chicago, IL, USA). Descriptive statistics were calculated and are expressed as means and standard deviation (SD). The frequency of USG use and the presence of educational programs in each population (pediatric and adult) were comparatively analyzed using linear-by-linear association. The P-value for statistical significance was set at 0.05 .

\section{RESULTS}

Of the 97 surveys distributed, 81 (83.5\%) were completed. Of these, 20 EDs (24.7\%) were level one emergency centers and the remaining 61 (75.3\%) were level two centers. The EDs had a mean of 4.9 (SD, 0.24) EM faculty members and 6.2 (SD, 0.50) residents in their EDs. The characteristics of each ED are shown in Table 1.

All respondents stated they had an ultrasound machine and could use it in their ED whenever required. The distribution of manufacturers' ultrasound machines in the participating EDs is also shown in Table 1. For adult patients, 82.7\% of respondents (67/81) reported that emergency physician-performed bedside USG was usually done daily; only four EDs (4.9\%) performed these USG fewer than once a week (Table 2). Seventy-nine EDs (97.5\%) reported performing a focused assessment with sonography for trauma, 65 (80.2\%) performed echocardiography, 62 (76.5\%) performed abdominal sonography, and 53 (65.4\%) performed ultrasound-guided central line insertions. In addition, 10 EDs (12.3\%) stated using sonography during peripheral intravenous catheterization. Only 19 EDs (23.6\%) performed pediatric USG daily. Thirty-five EDs (43.2\%) performed pediatric USG fewer than once a week; moreover, 10 (12.3\%) did not perform it at all despite having access to a machine. Thirty-seven EDs (45.7\%) reported per- 
Table 1. Demographics of the surveyed teaching hospitals

\begin{tabular}{|c|c|}
\hline Variable & No. $(\%)$ \\
\hline \multicolumn{2}{|l|}{ Level of emergency department } \\
\hline Level 1 & $20(24.7)$ \\
\hline Level 2 & $61(75.3)$ \\
\hline Level 3 & $0(0)$ \\
\hline \multicolumn{2}{|l|}{ No. of patients who visited the emergency department annually } \\
\hline$<20,000$ & $6(7.4)$ \\
\hline $20,000-29,999$ & $18(22.2)$ \\
\hline $30,000-39,999$ & $21(25.9)$ \\
\hline $40,000-49,999$ & $20(24.7)$ \\
\hline$\geq 50,000$ & $16(19.8)$ \\
\hline \multicolumn{2}{|l|}{ No. of residents in each hospital } \\
\hline$\leq 1$ & $9(11.1)$ \\
\hline 2 & $10(12.3)$ \\
\hline 3 & $4(4.9)$ \\
\hline 4 & $10(12.3)$ \\
\hline 5 & $5(6.2)$ \\
\hline 6 & $9(11.1)$ \\
\hline 7 & $7(8.6)$ \\
\hline 8 & $10(12.3)$ \\
\hline$\geq 9$ & $17(21.0)$ \\
\hline \multicolumn{2}{|l|}{ No. of faculty members } \\
\hline$\leq 2$ & $0(0.0)$ \\
\hline 3 & $20(24.7)$ \\
\hline 4 & $23(28.4)$ \\
\hline 5 & 15 (18.5) \\
\hline 6 & 15 (18.5) \\
\hline$\geq 7$ & $8(9.9)$ \\
\hline \multicolumn{2}{|l|}{ Presence of ultrasound machine } \\
\hline Yes & $81(100)$ \\
\hline No & $0(0)$ \\
\hline \multicolumn{2}{|l|}{ Manufacturer of machine $(n=92)^{a)}$} \\
\hline General Electric & $46(56.8)$ \\
\hline Philips & $14(17.3)$ \\
\hline SonoSite & $8(9.9)$ \\
\hline ZONARE & $6(7.4)$ \\
\hline Medison & $6(7.4)$ \\
\hline Siemens & $5(6.2)$ \\
\hline Others: HP (2), Aloka (2), Toshiba (1), Titan (1), Esaote (1) & $7(8.6)$ \\
\hline
\end{tabular}

a)Eleven participating emergency departments reported that they have two ultrasound machines.

forming focused assessment with sonography for trauma for pediatric patients in their EDs, and only 24 (29.6\%) had emergency physicians perform bedside pediatric echocardiography. Fortythree EDs (53.1\%) indicated that they performed bedside pediatric abdominal USG in their EDs; 35 (43.2\%) performed it on pediatric patients with suspected appendicitis, 14 (17.3\%) on patients with suspected testicular torsion, and 27 (33.3\%) on patients with suspected intussusception.

In total, 74.1\% of the participating EDs (60/81) had education programs for adult USG in residency training, whereas only 21\% (17/81) had programs for pediatric USG (Table 3). Table 4 shows the association between the frequency of ultrasonographic examinations and the presence of educational programs for USG. Of
Table 2. Use of ultrasound equipment in the emergency department

\begin{tabular}{lcc}
\hline Variable & For adults & For pediatric patients \\
\hline Frequency of use (/wk) & & \\
No use at all & $1(1.2)$ & $10(12.3)$ \\
$<1$ & $3(3.7)$ & $35(43.2)$ \\
$1-2$ & $2(2.5)$ & $10(12.3)$ \\
$3-4$ & $8(9.9)$ & $7(8.6)$ \\
$>5$ & $67(82.7)$ & $19(23.6)$ \\
Category of use & & \\
FAST & $79(97.5)$ & $37(45.7)$ \\
Echocardiography & $65(80.2)$ & $24(29.6)$ \\
Acute abdomen & $62(76.5)$ & $43(53.1)$ \\
Acute appendicitis & - -a) & $35(43.2)$ \\
Testicular torsion & - & $14(17.3)$ \\
Intussusception & - & $27(33.3)$ \\
Other & - & $11(13.6)$ \\
Central line access & $53(65.4)$ & $14(17.3)$ \\
Peripheral line access & $10(12.3)$ & $4(4.9)$ \\
Other procedural) & $32(39.5)$ & $11(13.6)$ \\
Musculoskeletal diseases & $11(13.6)$ & $10(12.3)$ \\
Other & $11(13.6)$ & $3(3.7)$ \\
\hline
\end{tabular}

Values are presented as number (\%).

FAST, focused assessment with ultrasonography in trauma patients.

${ }^{a}$ We did not survey about this value for adults. ${ }^{b}$ Bladder puncture, thoracentesis, paracentesis, abscess, and etc.

the total 81 EDs that participated, all 17 EDs with educational programs for pediatric USG answered that they performed pediatric ultrasound examinations almost every day. Of the remaining 64 EDs that lacked pediatric programs, only two (3.1\%) stated they performed pediatric USG almost every day, with 45 (70.3\%) performing it fewer than once a week. Similarly, all 60 EDs with education programs for adult patients reported performing USGs on adult patients almost every day, whereas, of the 21 EDs lacking adult programs, only seven (33.3\%) performed adult USGs every day.

The faculty members who most commonly participated in teaching EM residents how to perform USG were emergency physicians (67.9\%, 55/81). In total, $17.3 \%$ of participating directors (14/81) reported that they always provide quality assurance and feedback to their trainees; 23.5\% (19/81) lacked these processes. The training directors agreed that emergency physician-performed USG could shorten ED stays $(63 \%, 51 / 81)$ and improve the quality of care $(86.4 \%, 70 / 81)$ and patient satisfaction $(70.4 \%, 57 / 81)$ (Table 5).

\section{DISCUSSION}

EDs are categorized into three levels of care in Korea. Level one is the highest level, indicating the capacity to provide definitive, rapid care for all critical emergency situations. Level two is the type of ED found in large- and medium-sized hospitals that can manage common surgical problems and almost all illnesses, in- 
Table 3. Ultrasound education program

\begin{tabular}{|c|c|c|}
\hline Variable & $\begin{array}{l}\text { For } \\
\text { adults }\end{array}$ & $\begin{array}{c}\text { For pediatric } \\
\text { patients }\end{array}$ \\
\hline \multicolumn{3}{|c|}{ Presence of an ultrasound examination education program } \\
\hline Yes & $60(74.1)$ & $17(21)$ \\
\hline No & $21(25.9)$ & $64(79)$ \\
\hline \multicolumn{3}{|l|}{ Educational methods } \\
\hline Dispatch to another department or hospital & $19(23.5)$ & $3(3.7)$ \\
\hline Hands-on experience, including bedside teaching & $46(56.8)$ & $10(12.3)$ \\
\hline Conferences or lectures & $25(30.9)$ & $7(8.6)$ \\
\hline Workshops (courses) & $32(39.5)$ & $8(9.9)$ \\
\hline \multicolumn{3}{|l|}{ Trainer } \\
\hline Emergency physician & $55(67.9)^{\mathrm{a})}$ & $13(16)$ \\
\hline Radiologist & $13(16.0)^{\mathrm{a})}$ & $4(4.9)$ \\
\hline No trainer & $21(25.9)$ & $64(79)$ \\
\hline \multicolumn{3}{|l|}{ Predesignated record form ${ }^{b)}$} \\
\hline Yes & \multicolumn{2}{|c|}{$28(34.6)$} \\
\hline No & \multicolumn{2}{|c|}{$53(65.4)$} \\
\hline \multicolumn{3}{|l|}{ Quality assurance and/or feedback program ${ }^{\text {b) }}$} \\
\hline No confirmation process & \multicolumn{2}{|c|}{$19(23.5)$} \\
\hline Sometimes confirmed by EM faculty & \multicolumn{2}{|c|}{$28(34.6)$} \\
\hline Always confirmed by EM faculty & \multicolumn{2}{|c|}{$12(14.8)$} \\
\hline Sometimes confirmed by radiologist & \multicolumn{2}{|c|}{$20(24.7)$} \\
\hline Always confirmed by radiologist & \multicolumn{2}{|c|}{$2(2.5)$} \\
\hline
\end{tabular}

Values are presented as number (\%).

$E M$, emergency medicine; ED, emergency department.

a) Eight EDs answered that both ED faculty members and the radiologists provide

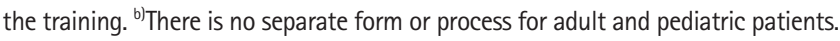

cluding acute coronary syndromes and strokes. All EM residency teaching hospitals have level one or two EDs. In 2000, the Emergency Medical Service Act designated the ultrasound machine as an essential piece of equipment in level one and two EDs; therefore, all academic EDs in Korea have ultrasound machines. However, in Daegu, Korea, 2010, a pediatric patient with suspected intussusception who could not receive an emergency USG examination died after visiting several hospitals, including an academic ED. This demonstrates that emergency pediatric ultrasound examinations are not always available in spite of the availability of ultrasound devices in all academic EDs in Korea. This situation may be common to many countries. ${ }^{6}$ To overcome this limitation, emergency physicians should be able to perform emergency USG; therefore, emergency ultrasound education programs should be incorporated into their training.

We have investigated the current practice of emergency USGs at academic EDs in Korea, showing that emergency pediatric USG use is much lower than that of adult USG in the ED. This finding might be affected by the fact that the number of pediatric patients who visit EDs is lower than the number of adult patients. However, the resolution of USG is higher in pediatric patients because they are smaller and thinner than adults; additionally, there is a stronger requirement for performing USG in pediatric patients
Table 4. The frequency of ultrasonography use according to the presence of education programs

\begin{tabular}{|c|c|c|c|c|c|c|}
\hline \multirow[b]{2}{*}{$\begin{array}{c}\text { Frequency } \\
\text { of use }\end{array}$} & \multicolumn{3}{|c|}{ For adult USG } & \multicolumn{3}{|c|}{ For pediatric USG } \\
\hline & $\begin{array}{c}\text { Education } \\
\text { program } \\
(+) \\
n=60\end{array}$ & $\begin{array}{c}\text { Education } \\
\text { program } \\
\qquad(-) \\
n=21\end{array}$ & P-value ${ }^{a)}$ & $\begin{array}{c}\begin{array}{c}\text { Education } \\
\text { program } \\
(+) \\
n=17\end{array}\end{array}$ & $\begin{array}{c}\text { Education } \\
\text { program } \\
\qquad(-) \\
n=64\end{array}$ & P-value \\
\hline$<1$ & $0(0)$ & $4(19.0)$ & $<0.001$ & $0(0)$ & 45 (70.3) & $<0.001$ \\
\hline $1-4$ & $0(0)$ & $10(47.7)$ & & $0(0)$ & $17(26.6)$ & \\
\hline$>5$ & $60(100)$ & $7(33.3)$ & & $17(100)$ & $2(3.1)$ & \\
\hline
\end{tabular}

Values are presented as number (\%).

USG, ultrasonography.

${ }^{a)}$ Calculated by linear by linear association.

Table 5. The directors' perceptions on the use of emergency physicianperformed ultrasonography

\begin{tabular}{lccc}
\hline Variable & Agree & No opinion & Disagree \\
\hline Shortens emergency department stay & $51(63.0)$ & $13(16.0)$ & $17(21.0)$ \\
Improves the quality of care & $70(86.4)$ & $10(12.3)$ & $1(1.3)$ \\
Improves patient satisfaction & $57(70.4)$ & $16(19.8)$ & $8(9.8)$ \\
\hline
\end{tabular}

Values are presented as number (\%).

than in adults because of concern over radiation exposure. In our $E D$, we have educational programs for both adult and pediatric USG, and USG use in adults and pediatric patients is similar although the number of adult patients is three times higher. We hypothesize that the lack of education programs for pediatric USG might affect the low use of USG in pediatric patients. Moore et al. ${ }^{6}$ reported that the primary reason for not implementing emergency physician-performed USGs is the lack of training for emergency physicians. In this study, we found a high association between the availability of education programs and the use of USG in both groups (pediatric and adult patients). Ultrasound training increases practitioners' confidence, which likely improves accessibility and/or use of USG on patients.

Bedside pediatric abdominal USG was not performed in approximately half of academic EDs $(46.9 \%, 38 / 81)$ in this study. Emergency physician-performed USGs of suspected testicular torsion and intussusception, which were regarded as pediatric emergencies, were only available in 17.3\% (14/81) and 33.3\% (27/81) of participating EDs, respectively. In addition, more than half of EDs $(56.8 \%, 46 / 81)$ did not perform USGs for suspected pediatric appendicitis. Given that even a novice physician without any USG experience can adequately perform a bedside, focused, emergency USG with an intensive, short USG training program, ultrasound training for pediatric-specific emergencies can facilitate using bedside emergency physician-performed pediatric USG. Our previous study reported good performance in novice emergency physician-performed USG for diagnosing intussusception 
after 2-hour focused training sessions with a sensitivity of 92.9\% and a specificity of $91.7 \% .{ }^{11}$ Riera et al. ${ }^{12}$ reported similar results (sensitivity, 85\%; specificity, 97\%).

More than $60 \%$ of training directors $(63 \%, 51 / 81)$ agreed that using emergency physician-performed USG shortens ED stays; this is supported by several reports. ${ }^{13,14}$ Most of the participating educational directors agreed that emergency physician-performed USG improves the quality of emergency care and patient satisfaction. Using bedside pediatric USG can provide an immediate diagnosis and treatment of life-threatening conditions. ${ }^{15,16}$ In cases of intussusception and testicular torsion, bedside USG can prevent bowel or testicular obstruction and ischemia in children by facilitating a timely reduction procedure. Furthermore, considering that many pediatric patients with suspected appendicitis still first undergo computed tomography scanning, an emergency physician-performed focused USG on suspected appendicitis would decrease patient exposure to radiation, which increases guardian and parental satisfaction.

Education programs for pediatric emergency USG in Korea are lacking. Education for adult USG is typically conducted in academic EDs; however, systematic educational programs administered by the KSEM are insufficient. Furthermore, in Korea, few academic EDs provide quality assurance and feedback (only $17.3 \%$ of participated EDs reported always providing quality assurance; $23.5 \%$ reported that they do not provide quality assurance). The KSEM has not yet designated pediatric USG as core content for emergency procedures; therefore, few educational directors of academic EDs in Korea indicated that they provide this education in their facilities. KSEM education committee members may have believed that it was premature to include pediatric USG in the core contents of emergency procedures; however, we suggest that it should be included, given that the effectiveness of focused emergency physician-performed pediatric USG has been proven, ${ }_{1}^{7-10}$ and the need for pediatric USG in the ED has been emphasized.

There are several limitations to this study. Although additional surveys were conducted for a complete enumeration survey, we did not receive responses from 16 of the academic EDs. In spite of several attempts to contact the nonresponsive educational directors by telephone, we could not contact them. As a result, there could be some response bias in spite of our excellent response rate (83.5\%). However, the nonresponders are likely to be small hospitals that lack educational programs or the active use of emergency physician-performed USG. Therefore, it is unlikely that the lack of responses significantly affected our results. As with all survey studies, this study was limited by the accuracy of the replies. Although the respondents in this survey were ED training directors, who are regarded as knowledgeable physicians based on their ultrasound use and educational background, it is not certain that the responses were accurate or that the directors themselves actually replied.

In conclusion, the distribution of ultrasound machines in academic EDs in Korea is high, and many training directors agree with the value of emergency physician-performed USG. Nevertheless, the availability of pediatric USG is still low, which is likely to be related to the lack of the training programs for treating pediatric patients.

\section{CONFLICT OF INTEREST}

No potential conflict of interest relevant to this article was reported.

\section{REFERENCES}

1. Ramirez-Schrempp D, Dorfman DH, Tien I, Liteplo AS. Bedside ultrasound in pediatric emergency medicine fellowship programs in the United States: little formal training. Pediatr Emerg Care 2008;24:664-7.

2. Use of ultrasound imaging by emergency physicians. Ann Emerg Med 2001;38: 469-70.

3. Accreditation Council for Graduate Medical Education. ACGME program requirements for graduate medical education in emergency medicine [Internet]. Chicago, IL: Accreditation Council for Graduate Medical Education; 2012 [cited 2013 Jul 15]. Available from: http://www.acgme.org/acgmeweb/Portals/0/PFAssets/2013-PR-FAQ-PIF/110_emergency_medicine_07012013.pdf

4. Cohen JS, Teach SJ, Chapman Jl. Bedside ultrasound education in pediatric emergency medicine fellowship programs in the United States. Pediatr Emerg Care 2012;28:845-50.

5. Counselman FL, Sanders A, Slovis CM, Danzl D, Binder LS, Perina DG. The status of bedside ultrasonography training in emergency medicine residency programs. Acad Emerg Med 2003;10:37-42.

6. Moore CL, Molina AA, Lin H. Ultrasonography in community emergency departments in the United States: access to ultrasonography performed by consultants and status of emergency physician-performed ultrasonography. Ann Emerg Med 2006; 47:147-53.

7. Shackford SR, Rogers FB, Osler TM, Trabulsy ME, Clauss DW, Vane DW. Focused abdominal sonogram for trauma: the learning curve of nonradiologist clinicians in detecting hemoperitoneum. J Trauma 1999;46:553-62. 
8. Verschelden P, Filiatrault D, Garel L, et al. Intussusception in children: reliability of US in diagnosis--a prospective study. Radiology 1992;184:741-4.

9. Vignon P, Dugard A, Abraham J, et al. Focused training for goaloriented hand-held echocardiography performed by noncardiologist residents in the intensive care unit. Intensive Care Med 2007;33:1795-9.

10. Chalumeau-Lemoine L, Baudel JL, Das V, et al. Results of shortterm training of naïve physicians in focused general ultrasonography in an intensive-care unit. Intensive Care Med 2009; 35:1767-71.

11. Kim JH, Kang HG, Lim TH, et al. Ultrasonography of suspected ileocolic intussusceptions performed by emergency medicine residents. J Korean Soc Emerg Med 2012;23:643-8.

12. Riera $A$, Hsiao AL, Langhan ML, Goodman TR, Chen L. Diagno- sis of intussusception by physician novice sonographers in the emergency department. Ann Emerg Med 2012;60:264-8.

13. Shih $\mathrm{CH}$. Effect of emergency physician-performed pelvic sonography on length of stay in the emergency department. Ann Emerg Med 1997;29:348-51.

14. Halm BM. Reducing the time in making the diagnosis and improving workflow with point-of-care ultrasound. Pediatr Emerg Care 2013;29:218-21.

15. Longjohn M, Wan J, Joshi V, et al. Point-of-care echocardiography by pediatric emergency physicians. Pediatr Emerg Care 2011;27:693-6.

16. Fox JC, Boysen M, Gharahbaghian L, et al. Test characteristics of focused assessment of sonography for trauma for clinically significant abdominal free fluid in pediatric blunt abdominal trauma. Acad Emerg Med 2011;18:477-82. 


\section{APPENDIX}

Survey: Ultrasonography use in academic emergency departments (EDs)

Thank you for your participating in this survey.

1) Does your ED have an ultrasound machine for use by emergency physicians in your ED?

$\square$ Yes

$\square$ No

2) What is your ultrasound machine's brand name?

$\square$ General electric

$\square$ PHILIPS

$\square$ SONOSITE

$\square$ MEDISON

$\square$ SIEMENS

¿ ZONARE

$\square$ ALOKA

$\square$ Other (specify):

3) How often do your emergency physicians perform the emergency ultrasonography in your ED?

3-1) For adult patients

口 No use at all

$\square<$ Once a week

$\square$ Once or twice a week

$\square 3$ To 4 times a week

$\square$ Almost every day (5 times or more a week)

3-2) For pediatric patients

口 No use at all

$\square<$ Once a week

$\square$ Once or twice a week

3 To 4 times a week

$\square$ Almost every day (5 times or more a week)

4) For what applications do emergency physicians in your ED perform ultrasonography (multiple-choice)

4-1) For adult patients

$\square$ Focused assessment with ultrasonography in trauma patients (FAST)

$\square$ Echocardiography

$\square$ Abdominal ultrasonography for suspected acute abdomen

$\checkmark$ Sono-guided central line insertion

$\checkmark$ Sono-guided peripheral line insertion

$\checkmark$ Other procedural (Abscess, Paracentesis, thoracentesis, bladder puncture, and etc.)

$\square$ Check for musculoskeletal disease

$\checkmark$ Other (specify):

4-2) For pediatric patients

$\square$ Focused assessment with ultrasonography in trauma patients (FAST)

$\square$ Echocardiography

Abdominal ultrasonography for suspected acute abdomen

$\square$ For acute appendicitis

$\checkmark$ For testicular torsion

$\square$ For intussusception

$\square$ Other (specify):

$\checkmark$ Sono-guided central line insertion

$\square$ Sono-guided peripheral line insertion

$\square$ Other procedural (Abscess, Paracentesis, thoracentesis, bladder puncture, and etc.)

$\square$ Check for musculoskeletal disease

$\square$ Other (specify):

5) Does your ED have a quality assurance and/or feedback program

$\square$ No confirmation process

$\checkmark$ Sometimes confirmed by EM faculty

$\square$ Always confirmed by EM faculty

$\square$ Sometimes confirmed by radiologist

$\square$ Always confirmed by radiologist

6) Does your ED have a ultrasound training program for emergency medicine residents

6-1) For adult ultrasonography

$\square$ Yes

$\square$ No

6-2) For pediatric ultrasonography

$\square$ Yes

$\square$ No

7) What kind of ultrasound education methods does your ED provide?

$\square$ Send to another department or hospital

$\square$ Hands-on experience, including bedside teaching

$\square$ Conferences or lectures

$\square$ Workshops (courses)

8) What faculty member most commonly participates in teaching EM residents how to perform ultrasonography?

$\square$ Emergency physician

Radiologist

$\square$ No trainer 
9) Does your ED have a pre-designated record form?

口 Yes

$\square$ No

10) Do you agree that the use of emergency physician-performed ultrasonography shortens ED stays?

$\square$ Agree

$\square$ No opinion

$\square$ Disagree
11) Do you agree that the use of emergency physician-performed ultrasonography improves the quality of care?
$\square$ Agree
$\square$ No opinion
$\square$ Disagree

12) Do you agree that the use of emergency physician-performed ultrasonography improves patients' satisfaction?

$\square$ Agree

- No opinion

๑ Disagree 